
consumer", Part IV Seafood from source to sonsumer products, Chapter 19, pp. 399-425.

(c) Torger Børresen (ed.)

\title{
Hurdle technology to ensure the safety of seafood products
}

Leroi $^{1,{ }^{*}}$ F., Amarita ${ }^{2}$ F., Arboleya ${ }^{2}$ J.C., Bjørkevoll ${ }^{3}$ I., Cruz $^{2}$ Z., Dousset ${ }^{6}$ X., Izurieta ${ }^{2}$ E., Joffraud J.J J $^{1}$, Lasagabaster $^{2}$ A., Lauzon ${ }^{4}$ H. L., Lorentzen ${ }^{3}$ G., Martínez de Marañón ${ }^{2}$ I., Matamoros ${ }^{, 6}$ S., Miranda ${ }^{2}$ I.,

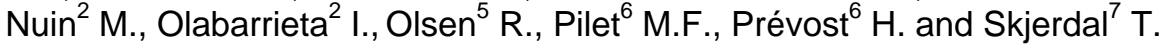

${ }^{1}$ Ifremer, France

${ }^{2}$.AZTI-Tecnalia, Spain.

${ }^{3}$ NIFA, Norway

${ }^{4}$ MATIS, Iceland.

${ }^{5}$ The Norwegian College of Fisheries, Norway.

${ }^{6}$ UMR INRA 1014 SECALIM, ENITIAA, France

${ }^{7}$ National Veterinary Institute, Norway

*: Corresponding author : F. Leroi, email address : Francoise.Leroi@ifremer.fr 


\section{Introduction}

The microbial safety and stability of most food, are based on an application of preservative factors called hurdles. Each hurdle implies putting microorganisms in a hostile environment, which inhibits their growth or causes their death (Leistner, 2000). Some of those hurdles have been empirically used for years to stabilize meat, fish, milk and vegetables. This sometimes leads to completely different product with its own new taste characteristics. Examples of hurdles in marine products are salt (salted cod, klipfish), smoke (cold or hot smoked salmon, herring), acids (marinated products, pickles), temperature (high or low), fermentative microorganisms (traditional Asian sauces) and more recently redox potential (vacuum-packed products). Those preservative factors have been studied for years, but a large amount of potential hurdles for food have already been described including organic acids, bacteriocins, chitosan, nitrate, lactoperoxidase, essential oil, modified atmosphere packaging..., as well as novel decontamination technologies such as microwave and radio frequency, ohmic and inductive heating, high pressure, pulsed electric field, high voltage arc discharge, pulsed light, oscillation magnetic field, ultraviolet light, ultrasound, X-ray, electrolyse $\mathrm{NaCl}$ water, ozone... (Kim et al, 1999 ; Weber, 2000 ; Mahmoud et al, 2006). Hurdles that have a positive effect by inhibiting microorganisms may have a negative one on other parameters such as nutritional properties or sensory quality, depending on their intensity. As an example, salt content in food must be high enough to inhibit pathogens and spoilage microorganisms, but not so high to impair taste. In order to lower the preservative level, the hurdle technology concept has been developed (Leistner, 1985), consisting in using combined hurdles to establish an additive antimicrobial effect, and even sometimes a synergetic one, thus improving the safety and the sensory quality of food.

For fish products manufactured in industrialised countries, the hurdle technology has been identified of the most interest for two groups of products :

- convenience products based on traditional products, like rehydrated salt-cured or dried fish. The raw material is a preserved semi-finished (PSFP) product but as the preservative is removed during processing, surviving pathogens in the raw material may recover. Minimising the survival of pathogens in the PSFP is therefore, beside the hygienic process conditions, necessary to ensure product safety.

- lightly preserved fish products (LPFP) which are uncooked or mildly cooked products, with low level of preservatives $(\mathrm{NaCl}<6 \% \mathrm{WP}, \mathrm{pH}>5)$, such as coldsmoked salmon (CSS), carpaccio, slightly cooked shrimp... LPFP are usually produced from fresh seafood and further processing involves one or a few additional steps that increase risk of cross contamination. The treatments are usually not sufficient to destroy pathogens, and, as several of these products are eaten raw, minimising the presence and prevent growth of pathogens is essential for the food safety.

Some microorganisms that do not represent a health risk for consumer may sometimes be responsible for organoleptic damages such as off-odours and taste, pasty texture, visual defaults... Preventing the growth of those spoilers microorganisms is therefore also a challenge.

This chapter focuses on five potential hurdles that might contribute to ensure the microbial safety and quality of those two groups of convenience products: a traditional hurdle (salt), three innovative hurdles (bioprotective microorganisms, chitosan and bioactive packaging) and a novel decontamination technology (pulsed light). Some examples of application that have been developed within the frame of the HURDLETECH project from the SEAFOODplus Integrated Project will be specifically addressed. 


\section{Salt hurdle in seafood processing}

Preservation methods like salt-curing and drying has been used for centuries to obtain fully preserved products and access to good, safe and nutritious food at all seasons and areas where the availability of fresh food is limited. Salt-cured cod, the precursor to klipfish, and known as the traditional products bacalao in Spain and bachalau in Portugal, has had this position for centuries, but today salt-cured cod is popular due to its sensory properties rather than lack of availability of other foods. However, the consumption decreases, and one important reason is the time consuming to preparation. The salt-cured cod must for most dishes be rehydrated (soaked in water) for at least 24 hours in order to lower the salt concentration from app $20 \%$ to $2.5-3.0 \%$ before the meal can be prepared. Commercially soaked products have been developed in order to meet the demands for convenient products with the traditional taste of salt-cured cod.

Salt-cured and dried fish products are generally regarded as safe, even though they are produced in relatively open houses with limited possibilities to regulate temperature and maintain good hygienic conditions. It is considered that salt-curing is an effective barrier against bacteria. However, rehydrated salt-cured cod spoils rapidly, and it is found that this is due to growth of Psychrobacter spp. These bacteria are present on the skin of fresh fish, survive in a non-growing mode during saltcuring, but recover and grow during and after rehydration (Bjørkevoll et al, 2003). A number of other bacteria have also been found to survive the salt-curing step (Vilhelmson, 1997 ; Skjerdal et al, 2002 ; Barat et al, 2006). Listeria spp. and Staphylococcus spp. are occasionally found in salt-cured cod products (Pedro et al, 2004), but it has not been clear whether these bacteria survive in the fish if introduced to the fish prior to salt-curing, or only when they are introduced directly to the salt-cured cod shortly before the sample is taken. Commercially rehydrated saltcured cod is stored for some days from rehydration to consumption, indicating that surviving pathogenic bacteria may get the opportunity to grow before the consumer eats the product. Another element is that the salt-curing and rehydration processes are usually carried out in different countries. For risk management in a farm-to-fork perspective, it is therefore essential to know whether the salt-curing step eliminate the pathogenic bacteria or not. The objective for our studies have been to investigate how salt-curing influence the survival of growth of pathogenic bacteria, primarily Listeria spp., that are introduced at different steps in the production process of saltcured cod. Salt-cured cod products contain $15-21 \%$ salt, and the salt-curing period lasts for approximately 3 weeks.

\section{Survival and growth of Listeria spp. during salt-curing and rehydration/soaking}

The survival of Listeria spp. and Staphylococcus spp. after exposure to high saltconcentrations was performed in a semi-quantitative study in order to investigate whether it is likely that these bacteria survive salt-curing. The surrogate pathogen bacteria Listeria innocua and Staphylococcus xylosus were used as indicators for the pathogenic bacteria Listeria monocytogenes and Staphylococcus aureus, respectively. Those bacteria were inoculated in levels from $\log _{10} 5$ to $\log _{10} 9 \mathrm{CFU} \mathrm{ml}{ }^{-1}$ in fish juice supplemented with $\mathrm{NaCl}$ in the range $0-21 \%$ and stored for up to three weeks at $4^{\circ} \mathrm{C}$. The fish juice was prepared by the method of Dalgaard (1995) from wild-caught, newly killed cod (Gadus morhua). The results are shown in Table 15.1. Li. innocua survived at all inoculation and stress levels for at least 21 days of 
incubation at $4^{\circ} \mathrm{C}$. Similar experiments with $\mathrm{Li}$. innocua and six Li. monocytogenes strains and inoculation levels of $2.5 \log _{10} \mathrm{CFU} \mathrm{ml}{ }^{-1}$ showed that most strains survived for at least 60 days in $21 \% \mathrm{NaCl}$ (results not shown). Surviving S. xylosus was also detected after 21 days at all stress conditions when the highest inoculation level was used, but not for lower inoculation levels (Table 15.1). Thus, both Staphylococcus and Listeria are able to survive during exposure to high salt-concentrations.

The survival of $L i$. innocua in cod during salt-curing and rehydration was further investigated in a quantitative study by inoculating newly wild caught cod with 1 to 6 $\log _{10}$ CFU g ${ }^{-1}$ prior to salt-curing. The obtained results from eight experiments are shown in Table 15.2. After salt-curing and rehydration, Li. innocua was present in the inoculated fish samples in levels less than $1 \log _{10}$ CFU g ${ }^{-1}$ lower than the corresponding inoculation level. The growth of $\mathrm{Li}$. innocua during storage of the rehydrated fish samples at 4 and $8^{\circ} \mathrm{C}$ were also analysed. When the fish was stored at $8^{\circ} \mathrm{C}$, growth of $\mathrm{Li}$. innocua was observed in most experiments within five days, and in all experiments after ten days. In fish stored at $4^{\circ} \mathrm{C}$, on the other hand, growth was not observed in any of the experiments after five days, but in three of the experiments after ten days (experiments 2-4). The increase in Li. innocua levels between five and ten days in experiment 2-4 were within $1 \pm 0.3 \log _{10} \mathrm{CFU} \mathrm{g} \mathrm{g}^{-1}$ in fish stored at $4^{\circ} \mathrm{C}$. In experiment 1 , there might have been a similar but undetected growth, as the inoculation level was below the detection level in the quantitative analysis. Li. monocytogenes and Li. innocua showed similar results (experiments 68). In conclusion, Listeria spp. are able to survive in cod during salt-curing, and after some time to recover and grow after rehydration. The lag phase indicate that Listeria introduced to the fish prior to salt-curing has limited impact on the food safety risk in rehydrated salt-cured cod unless it is stored at abuse temperature.

\section{The impact of contamination point of Listeria spp.}

The rehydration process of salt-cured cod products is a source of contamination, as usually done in non aseptic conditions and as nutrients released from the fish give favourable conditions for bacteria (Skjerdal et al, 2002). The growth kinetics of $L i$. innocua introduced to the fish from the rehydration water was therefore investigated and compared to that for Li. innocua introduced prior to salt-curing. The results obtained with fish inoculated with 10-500 CFU g ${ }^{-1}$ of $L i$. innocua are showed in Fig. 15.1. In fish inoculated during rehydration, the observed lag phases of Li. innocua were relatively short: two-four days at $4^{\circ} \mathrm{C}$ and two days at $8^{\circ} \mathrm{C}$. In fish that was inoculated prior to salt-curing, on the other hand, the lag periods were approximately seven and two-four days when the fish was stored at 4 and $8^{\circ} \mathrm{C}$, respectively. As in earlier experiments, the growth rate of $L i$. innocua was significantly higher at 8 than at $4^{\circ} \mathrm{C}$. From a practical point of view, the results illustrate that Listeria introduced to the fish during rehydration has the potential to grow to higher numbers, i.e. reaches the infective dose earlier than Listeria introduced to the fish prior to salt-curing, and thereby represents a higher food safety risk.

\section{Effect of preservatives on shelf life and Listeria innocua growth of rehydrated salt-cured cod}

Vacuum packing and some preservatives are found to inhibit growth of Psychrobacter spp. and thereby prolong the sensory shelf life of rehydrated saltcured cod (Skjerdal et al, 2002 ; Fernández-Segovia et al, 2003 and 2006 ; 
Magnusson et al, 2006). In the present project, the effect of these treatments on Li. innocua growth in rehydrated salt-cured cod was investigated. The results obtained with fish inoculated with app. $1 \log _{10} \mathrm{CFU} \mathrm{g} \mathrm{g}^{-1}$ and stored at $8^{\circ} \mathrm{C}$ are shown in Table 15.3. The Li. innocua growth was delayed by sodium benzoate and sodium sulphite, but not by vacuum packing.

The shelf life of rehydrated salt-cured cod was estimated based on Psychrobacter content and sensory analysis (results not shown). The sensory shelf life of preserved salt-cured cod was, in case of vacuum packed, sodium benzoate and sodium sulphate treated samples, longer than the time period required for a 100 fold doubling of Listeria in the fish, indicating that the fish may become unsafe for vulnerable consumers before the fish is sensory spoiled.

\section{Concluding remarks}

Salt-curing of cod is not an effective barrier against Listeria spp., but leads to a longer lag-phase for the Listeria spp. growth after rehydration. The lag-phase becomes shorter and the growth rate faster when the fish is stored at abuse temperature. Listeria spp. introduced to the fish during rehydration, i.e. bacteria that have not been through the salt-curing process, have a shorter lag-phase. Some of the treatments that extend the sensory shelf life of rehydrated salt-cured cod inhibit the growth of Listeria but in a lower extend. They may therefore lower the food safety of the products because the products may become unsafe before they are sensory spoiled. These aspects should be considered in risk management of commercially rehydrated salt-cured cod products.

\section{Biopreservation of lightly preserved seafood products}

Biopreservation is a technology used to extend the shelf life and/or control the growth of pathogenic flora of refrigerated products by the inoculation of bacteria selected for their inhibition properties towards undesirable bacteria. In non-fermented food like LPFP, these bacteria should not modify the organoleptic and health qualities of the product. Lactic acid bacteria (LAB) are usually chosen for these applications as they produce a wide range of inhibitory compounds such as organic acids, hydrogen peroxide, diacetyl and bacteriocins. In addition, they are associated to fermented products and thus have the GRAS (generally recognized as safe) status granted by the US-FDA (US Food and Drug administration) and for some of them the QPS (qualified presumption of safety) status given by the European Food Safety Authority (www.efsa.europa.eu/). LAB also benefit from an healthy image associated with dairy products (Rodgers, 2001).

\section{Use of lactic acid bacteria to control pathogenic flora in lightly preserved fish products}

LPFP are highly perishable products. The major risk associated with LPFP is the pathogenic bacteria $L i$. monocytogenes responsible of listeriosis a food-borne disease generally associated with a high mortality rate (20-40\%). Li. monocytogenes has frequently been isolated from LPFP products like CSS (Jorgensen and Huss, 1998 ; Hoffman et al, 2003 ; Nakamura et al, 2004 ; Miettinen and Wirtanen, 2005). The contamination comes from raw fish or can occur during the process (Huss et al, 
2000). Li. monocytogenes is of special concern to the CSS industry because it is not destroyed by the different stages of processing (Ribeiro Neunlist et al, 2005) and is able to grow at low temperature in presence of high $\mathrm{NaCl}$ concentration and in anaerobic conditions (Cornu et al, 2006).

It has been shown that the bacterial flora of CSS is dominated by LAB like Carnobacterium maltaromaticum (previously named as $\mathrm{Cb}$. piscicola) and Lactobacillus spp. at the end of the storage (Leroi et al, 1998). For that reason, protective cultures are usually selected among these bacteria. Moreover, many LAB from the genus Carnobacterium and Lactobacillus are able to produce bacteriocins active against $\mathrm{Li}$. monocytogenes (Drider et al, 2006). Several strains of $\mathrm{Cb}$. maltaromicum have been successfully tested to prevent the growth of $L i$. monocytogenes in CSS for up to 30 days at chilled temperature (Nilsson et al, 1999 ; Katla et al, 2001 ; Duffes et al, 1999 ; Yamazaki et al, 2003). Other species like Lb. sakei, $L b$. casei or $L b$. plantarum have also been used to limit $L i$. innocua development in this product (Vescovo et al, 2006). In most of these studies, inhibition can be attributed to the production of bacteriocins with anti-listerial activity (for a review, see Drider et al, 2006). However, a strain of $C b$. maltaromicum exhibits an anti-listerial activity due to nutrient competition (Nilsson et al, 2005).

In the HURDLETECH project, three anti-listerial strains selected from a previous work, Cb. maltaromaticum V1 and SF668, and Cb. divergens V41 were tested. These strains produce one or two bacteriocins that have been totally or partially characterized (Bhugaloo-Vial et al, 1996 ; Métivier et al, 1998). Their inhibition activity have been shown with the agar diffusion method on Petri dishes towards 57 strains of $\mathrm{Li}$. monocytogenes representative of the smoked-salmon industry (Brillet et al, 2004).

To confirm these observations in the product, each Carnobacterium strain was tested in coculture with a set of 5 strains of $\mathrm{Li}$. monocytogenes at respective levels of $10^{5}$ and $10^{2} \mathrm{CFU} \mathrm{g}^{-1}$ in sterile CSS during vacuum storage for nine days at $4^{\circ} \mathrm{C}$ and 19 days at $8^{\circ} \mathrm{C}$ (with a temperature break of $2 \mathrm{~h}$ at $20^{\circ} \mathrm{C}$ after 19 days). The growth of $L i$. monocytogenes strains alone reached $10^{5}$ to $10^{6} \mathrm{CFU} \mathrm{g}{ }^{-1}$ at the end of the storage. It was maintained respectively below 50 and 100 CFU g ${ }^{-1}$ with Cb. divergens V41 and Cb. maltaromaticum V1 whereas a reduction of 1 to $1.5 \log C F U g^{-1}$ was observed with $\mathrm{Cb}$. maltaromaticum SF668 (Figure 15.2). The inhibition activity of $\mathrm{Cb}$. divergens V41 in CSS was clearly attributed to the divercin V41 production (Richard et al, 2003), although the bacteriocin could not be detected in the product, as a bacteriocin negative mutant of $\mathrm{Cb}$. divergens V41 did not inhibit growth of Li. monocytogenes.

\section{Use of lactic acid bacteria to control spoilage flora in lightly preserved fish products}

The efficacy of LAB to control spoilage flora in food products and particularly in fish products is not well documented. Leroi et al (1996) significantly increased the shelflife of smoked-salmon slices by inoculating them with strains of Carnobacterium spp., but results varied depending on the batch treated (Leroi et al, 1996). Only a slight extension of the smoked-salmon shelf-life was obtained with $\mathrm{Cb}$. maltaromaticum (Paludan-Muller et al, 1998). No sensory improvement was found in cooked shrimps and no inhibition of the specific Gram-positive spoilage bacteria Brochothrix thermosphacta was observed (Laursen et al, 2005). However, recently, Altieri et al (2005) succeeded in inhibiting Pseudomonas spp. and P. phosphoreum in vacuumpacked fresh plaice fillets at low temperatures by using a Bifidobacterium bifidum 
starter. A French patent was also developed for the biopreservation of cooked shrimps using the strain of Lactococcus lactis (Daniel and Lorre, 2003). It is used in France on cooked peeled shrimps stored under modified atmosphere to extend the shelf-life of the products (Meyer, 2005). However no information concerning its mechanisms of inhibition and its effect on the quality of the product is available.

The strain $\mathrm{Cb}$. divergens $\mathrm{V} 41$, which was selected in the HURDLETECH project for its inhibition activity towards $\mathrm{Li}$. monocytogenes in CSS, was inoculated on commercial CSS slices from four different producers to evaluate its impact on the natural flora. The results showed that when the natural microflora was initially weak (two batches $<20 \mathrm{CFU} \mathrm{g}{ }^{-1}$ ), Cb. divergens V41 quickly reached $10^{7-8} \mathrm{CFU} \mathrm{g}^{-1}$ and a slight inhibition of endogenous Enterobacteriaceae, lactobacilli and yeasts was observed (Figure 15.3). On the opposite, when the natural microflora was initially high ( 2 batches $>10^{4-5} \mathrm{CFU} \mathrm{g} \mathrm{g}^{-1}$ ), no effect on the microflora was detected (Brillet et al, 2005). Considering these results, this strain could not be used to prevent the growth of spoilage flora in CSS, but its interest on other LPFP should be tested as the spoilage flora is highly variable among the different products.

The collection of protective cultures available in the HURDLETECH project was widen by new $L A B$ strains recently isolated from various marine products. These strains were selected on their capacity to inhibit spoiling and pathogenic, Grampositive and Gram-negative marine bacteria. In order to obtain LAB strains competitive with psychrotrophic spoilage, the isolation was performed at $8^{\circ} \mathrm{C}$ and the strains growing at temperature up to $30^{\circ} \mathrm{C}$ were eliminated. The screening led to the selection of 52 psychrotrophic strains that were clustered on seven groups, on the basis of their inhibition spectrum and identification at genus level. One strain per group was lastly selected and identified by sequencing of the 16S rRNA gene as Leuconostoc gelidum (3 strains), Lactococcus piscium (2 strains), Lactobacillus fuchuensis (1 strain) and Carnobacterium alterfunditum (1 strain).

These seven strains were used for an application in cooked tropical shrimps where their ability to grow in the product and to control the spoilage was evaluated. Each LAB strain was inoculated at a level of $10^{5}$ CFU $g^{-1}$ on two batches of shrimps (different wild or farmed species). The shrimps were cooked, inoculated and stored at $8^{\circ} \mathrm{C}$ for 28 days under vacuum packaging. For each trial, a non-inoculated sample was used as control. After seven and 28 days of storage, samples were analysed for sensorial quality (seven trained judges for odour descriptors and spoiling level) and for microbiological quality. For sensory evaluation, a quality index (QI) was calculated, based on the percentage of judges considering the product as non spoiled, lightly spoiled and strongly spoiled. A QI up to 2 corresponds to a spoiled product (rejected by most of the trained panel).

Figure 4 shows (batch 1), that after seven days, the control was considered as non spoiled. The samples inoculated with Le. gelidum and Lc. piscium strains were the closest to the control. On the opposite, samples inoculated with $L b$. fuchuensis and $C b$. alterfunditum were considered as lightly or strongly spoiled. After 28 days, the control was considered as strongly spoiled whereas the samples inoculated with Le. gelidum EU2247 and EU2262 kept their fresh initial sensory quality. Those two strains as well as the two Lc. piscium also delayed the spoilage of shrimp in batch 2 .

Lactic acid flora counts confirmed that the seven inoculated LAB strains were at the expected level, and were able to grow during the storage (data not shown). Total mesophilic flora, total psychrotrophic flora and enterobacteria increased in the control and in the inoculated samples, without showing any correlation with the sensory parameters. 
To conclude, two Le. gelidum strains greatly extended the shelf-life of both batches of shrimps, two $L c$. piscium strains had a moderate effect, two were spoilers $(L b$. fuchuensis and $C b$. alterfunditum) and the last one (Le. gelidum) showed highly variable results depending on the batch considered.

Additional selection properties of LAB used in biopreservation of lightly preserved fish products

Besides their ability to prevent the growth of pathogenic or spoiling flora, other properties of the protective culture must be characterized for an application in food. First, the protective cultures should not have spoilage activities and even induce noteworthy organoleptic changes in the product. $L A B$ from the genus Carnobacterium have often been selected for the biopreservation of CSS because they are usually described as non-spoiling organisms (Paludan-Muller et al, 1998 ; Nilsson et al, 1999 ; Brillet et al, 2005). On the opposite, some species of Lactobacillus are responsible for specific spoiling activities (Stohr et al, 2001). However, the effect of the protective strains on the organoleptic qualities of the products is rarely investigated in biopreservation studies.

In the HURDLETECH project, experimentations were performed to evaluate the organoleptic changes caused by the inoculation of the protective Carnobacterium strains in CSS. These tests were investigated with the three strains of Carnobacterium on sensory properties and physico-chemical parameters in sterile CSS stored in the conditions previously described. The results showed that after three weeks of storage, none of the three strains acidified the product, produced total volatile basic nitrogen nor caused sensory spoilage. The same experiments were performed on four commercial CSS batches inoculated and stored in the same conditions and results confirmed that $\mathrm{Cb}$. divergens V41 did not induce major organoleptic nor physicochemical changes in the product.

For the seven $L A B$ recently selected, the results presented previously showed that $\mathrm{Lb}$. fuchuensis and $\mathrm{Cb}$. alterfunditum strains are not retained for biopreservation of shrimps as they caused a notable spoilage after seven days of storage at $8^{\circ} \mathrm{C}$. For the other strains, results are variable depending on the trial tested, but strains EU2247 and EU2262 (Le. gelidum) were the best candidates for a food application.

\section{Regulation concerning the use of bioprotective culture in lightly preserved fish products}

The application of LAB for the biopreservation of seafood products is slightly different from the traditional use of lactic starters in fermented products. However at this time, there is no regulation in Europe concerning the application of already known positive flora in food products except the directive 94/40/EC (European-Commission, 1994) that is applied to micro-organisms coming in the food chain from animal feeding (probiotic LAB). The regulation "novel foods" (Regulation 258/97/EC, EuropeanParliament-and-Council, 1997) is suitable for genetically modified microorganisms, but does not include the use of already characterized LAB in the food chain (Wessels et al, 2004). The European Commission has written a working paper (EuropeanCommission, 2003) that proposes a decision tree for the determination of the QPS status. Some of the main conditions are the taxonomic information available on the strain, the exclusion of pathogenic potential and production of undesirable metabolites, and evidence of the absence of acquired antibiotic resistance. 
In order to forecast the emerging European regulation concerning the safety assessment of the LAB strains for the biopreservation of seafood products, some safety properties were investigated within the HURDLETECH project, like the production of biogenic amines, and the antibioresistance. The production of histamine has not been detected after culture in histidine containing culture media for any of the strains tested. These results have been confirmed during the storage of inoculated smoked salmon for the three inhibiting Carnobacteria (Brillet et al, 2005). The antibiotic resistance observed at this time on the strains are usually described on these genus as non transmissible, some results are still in acquisition.

\section{Conclusion}

Results in the HURDLETECH project have shown that biopreservation is a very promising additional hurdle to ensure quality and safety of convenient seafood products. When the target is clearly identified (Li. monocytogenes for instance), the strains selected in the project are quite effective whatever the seafood product tested and we now have to bring the biopreservative technology to a stage where it can become available for the industry.

Concerning the spoilage, this technology has to be tailor-made for each industry as spoiling microorganisms vary within plants, depending on the hygienic conditions.

At the moment, no strain is performing to inhibit spoiling and pathogens at the same time. More work is needed to use mixed LAB cultures to master both quality and safety.

\section{Antimicrobial compounds}

Emergence of psychrotrophic food-borne pathogens has been a main concern in either ready to cook or to eat processed product. Based on this fact, reevaluation of food preservation methods is unavoidable matter. Therefore, the introduction of new or improved methods that comply with some current needs as chilled products with low levels of artificial preservatives is essential. In this context, the food industry and food research have driven towards the use of "natural" ingredients, i.e. naturally produced preservatives (biopreservatives).

Biopreservation often implies the use of $L A B$, their metabolic products or both to improve safety and quality of foods that are not generally considered fermented (Montville and Winkowski, 1997). The use of other antimicrobial compounds of plant, animal or microbial origin is also considered in biopreservation (Ray, 1992). Typical examples of these compounds are lactoperoxidase (milk), lysozyme (egg white, figs), saponins and flavonoids (herbs and spices) as well as chitosan (shrimp shells). Previously in this chapter, biopreservation and different applications have been described and therefore, at this point, the use of chitosan as a biopreservative will be addressed.

Chitosan, a natural polymer derived from crustacean shells after deacetylation of chitin, has been considered a potential novel food preservative due to its biodegradability, non-toxicity (Coma et al, 2002) and capacity to inhibit the growth of several bacteria and fungi in vitro (Roller and Covill, 1999). The mechanism of the antimicrobial activity of chitosan involves extensive cell surface alterations, changing 
membrane permeability with loss of barrier function (Helander et al, 2001). As a chelating agent, chitosan has the ability to selectively bind trace metals, which prevents production of toxins and microbial growth (Cuero et al, 1991). Regarding regulatory issues, chitosan is considered as a GRAS product in USA and in some countries, such as Corea and Japan, it has been incorporated into food products as a functional ingredient. However, chitosan is not currently regulated in Europe for food applications although it has been used in the food industry as a safe and natural fat digestion and trapped lipid compound (Coma et al, 2002).

The inhibitory action of chitosan has been reported widely in the scientific literature, mainly on the basis of in vitro trials against individual microorganisms (Gemma and Du, 1996 ; Genta et al, 1997 ; Cruz et al, 2006). However, the evidence in the literature regarding antimicrobial activity is contradictory. Reported minimum inhibitory concentrations for same species vary several orders of magnitude (Roller, 2002). These variations were suggested to be due to different types of chitosan (e.g. degree of acetylation, chain length and concentration used), the testing conditions (e.g. pH, temperature, medium) and target organism (Roller, 2003). Therefore, the success of chitosan's application will be a result of an appropriate parameter selection. Due to its antimicrobial properties, chitosan has been proposed as a novel food preservative (Chen et al, 1998 ; Rhoades and Roller, 2000 ; Shahidi et al, 1999 ; Tsai et al, 2000). However, only few investigations have been carried out in seafood products. Chitosan has been applied to lightly-salted and dried horse mackerel (Ahn and Lee, 1992), fresh fish fillets (Skonberg, 2000), shrimps (Simpson et al, 1997) salmon (Sathivel, 2005; Tsai et al, 2002), oysters (Chen et al, 1998), cod and herring (Jeon et al, 2002).

It can be foreseen that the application of chitosan in food matrixes could lead to decreased antimicrobial activity compared to in vitro tests due to interactions with different compounds, such as proteins and fats (Rhoades and Roller, 2000). Neutralisation of antimicrobial property has also been reported for other natural compounds, lysozyme, bacteriocins such as sakacin K (Leroy and De Vuyst, 1999) and curvacin (Verluyten et al, 2002). This phenomenon has been confirmed for LPFP within the HURDLETECH project of the SEAFOODplus IP where the evaluation of the antimicrobial activity of several chitosan formulations was conducted. In a microwell assay, some chitosan preparations (C4 and C8: low and high viscosity dissolved in acid) were found to be inhibitory to several pathogenic and fish spoilage bacteria, but generally influenced by $\mathrm{pH}$ and temperature when tested $(0.02 \% \mathrm{w} / \mathrm{v})$ in a model liquid system at 8 and $15^{\circ} \mathrm{C}$ (Fig. 5). Interestingly, growth of the protective culture $\mathrm{Cb}$. divergens V41 was not inhibited in presence of chitosan, but to the contrary it was apparently stimulated under some conditions (Fig.5). Antimicrobial effectiveness of chitosan coatings on real products was not as promising as the in vitro results suggested. Chitosan concentrations ranging from 0.002 to $0.2 \%(\mathrm{w} / \mathrm{v})$ showed a drop of $5 \mathrm{log}$ CFU ml ${ }^{-1}$ on Li. innocua counts in CSS juice while only a reduction of 1 log CFU $\mathrm{cm}^{-2}$ was induced in CSS coated with chitosan $(2 \% \mathrm{w} / \mathrm{v})$ and maintained for five days. When the same coating was applied on surimi products the cell inactivation was greater reaching a 4 log-drop in Li. innocua counts which was maintained during the 20 days of storage. Therefore, the ability of chitosan to reduce Li. innocua counts and to inhibit microbial growth does not only vary from in vitro tests to studies performed in seafood products, but is influenced by the type of food matrix.

Extensive work is required for a better understanding of the chitosan antimicrobial efficacy and before a commercial exploitation of chitosan as a novel preservative can occur. The studies should also be focused on the possible changes in the organoleptic and textural properties of the real products. 


\section{Antimicrobial packaging}

Active packaging is one of the innovative food packaging concepts that have been introduced as a response to market trends and the continuous changes in current consumer preferences towards mildly preserved, fresh, tasty and convenient foods with a prolonged shelf-life. Active packaging can be defined as "a type of packaging that changes the condition of the packaging to extend shelf-life or improve safety or sensory properties while maintaining the quality of the food".

Packaging regulations require compounds in contact with food to be on approved lists of compounds. Traditionally, a well functioning food packaging should be more or less inert. The overall migration limit of substances from packaging into the food was set at a maximum of $60 \mathrm{mg}$ per $\mathrm{kg}$ of food. This may be said to be inconsistent with the objective of active packaging that releases substances in order to extend shelf-life or improve quality. Therefore a new approach of packaging regulations was required.

The aprovement in 2004 of the EU Framework Regulation 1935/2004 on materials and articles intended to come into contact with food, triggered the serious research in this area in Europe. In this regulation the active packaging concept was defined for the first time, among other basic definitions. This is only a starting point, legislation about active packaging materials is still in elaboration progress. The publication of the new legislation in active packaging (2007/2008) will enhance the competitiveness of the European food industry, especially with the USA, Australia and Japan.

\section{Antimicrobial packaging description}

The term antimicrobial packaging covers any packaging technique used to control microbial growth in a food product. This concept includes mostly packaging materials (where the antimicrobial material is incorporated to the surface of the plastic films) and edible films or food coatings that contain antimicrobial activity. The antimicrobial efficiency can be given by preservatives that are released slowly from the packaging materials to the food surface or by preservatives that are firmly fixed and do not migrate into the food products. Both techniques are assumed to control growth of undesirable microorganisms if there is a good and intensive contact between the food product and the packaging material. In antimicrobial films and coatings either, the functional groups that have antimicrobial activity (e.g. bacteriocins) are added and immobilized on the surface of a polymer film which is in contact with the food surface, or the antimicrobial activity comes from the polymer itself used as filmforming entity or coating (e.g. chitosan).

\section{Chitosan as potential polymer for antimicrobial packaging}

As explained earlier, chitosan is a high-molecular weight cationic polysaccharide that exhibits antibacterial and antifungal activity. The advantage of using this polymer as part of an active packaging, apart of these characteristics, is its good film-forming properties. Several studies have been made about the film forming ability of chitosan (Butler et al, 1996). Unfortunately chitosan films are brittle (Suyatma et al, 2005) so there is a need of adding a plasticizer which will increase the free volume in the matrix. This affects the film ductility and handling properties positively but has a negative effect on barrier properties, thus a compromise between mechanical properties and barrier properties must be found (Olabarrieta, 2005). Chitosan forms 
tough, long lasting, flexible, transparent films which resemble plastic films. Chitosan film-forming and physicochemical properties will depend on the chitosan production process (Nadarajah et al, 2006) film-casting solvent (Caner et al, 1998), degree of deacetylation (Hwang et al, 2003), molecular weight (Mw) (Park et al, 2002 ; Hwang et al, 2003), drying conditions (Srinivasa et al, 2004) and plasticizer used (Caner et al, 1998). Chitosan films appear to be a promising prospect for edible films. In addition to its antimicrobial properties, due to its good gas barrier properties, chitosan coating can be expected to modify the internal atmosphere as well as decrease the transpiration losses. Therefore, the use of chitosan coating and films in food packaging applications could result in a delay in ripening and control of decay.

Within the HURDELTECH project, chitosan films were successfully produced. Glycerol and polyethylenglycol (PEG) were used in order to make the films flexible. The mechanical tests showed a great improvement in film elasticity for films with glycerol, whereas the improvement for PEG films was not as extensive. The addition of plasticizers to the initial chitosan formulations did not affect the antimicrobial activity of the chitosan film-forming solution. However, their films were very hydrophilic and sensitive to humidity. It is a challenge to develop chitosan-based antimicrobial films that are less sensitive to humidity. Further research should be directed towards maintaining the oxygen barrier and antimicrobial properties of chitosan films while improving water-vapour barriers and mechanical properties.

To conclude, chitosan shows potential to be used as part of an active packaging together with e.g. synthetic plastic films. The biopolymer film could be incorporated into the polymer matrix or absorbed onto the film surface by spraying, dipping or coating after a surface modification to improve adhesion between the different materials. Research has shown that chitosan based coatings and films could help to obtain less perishable food products. However, as regards seafood product applications, very few references have been found with chitosan/plastic active systems. Thus, further research is needed in this area.

\section{Pulsed light as a novel decontamination technology}

\section{Pulsed light technology description}

Pulsed light technology is a novel non-thermal decontamination process which consists of a successive repetition of high power pulses of broadband emission light. The emitted light spectrum includes wavelengths from 200 to $1000 \mathrm{~nm}$ with a considerable amount of light in the short-wave UV spectrum (Wekhof, 2000).

For the emission of a single light pulse, the electric power is stored in an energy storage capacitor and later released quickly to a Xenon lamp (Wekhof, 2000). Then, this lamp emits short duration (Lasagabaster and Martínez de Marañón, 2006) and high intensity light flashes that are transmitted to the surface of the products (Figure. 6 ). Even though the peak power of each pulse is high due to its short duration, the total pulse energy is relatively low. Therefore, since the average power requirement for a pulsed light treatment is moderate, it can be considered economical (Dunn et al, 1995).

Pulsed light technology could be applied as an alternative method to traditional thermal and chemical treatments to improve the safety and increase the shelf life of foodstuffs. However, since penetration capability of the light is poor, pulsed light technology could be limited to reduce microbial contamination of the surface of solid products (e.g. seafood products), clear liquids, processing devices (e.g. seafood processing chain) or packaging materials. Moreover, packed products could also be 
decontaminated whenever pulsed light is optimally transmitted through the packaging materials (Dunn et al, 1997). The US-FDA (FDA, 2003) approved the use of pulsed light technology "for production, processing and handling of foods" up to light doses of $12 \mathrm{~J} . \mathrm{cm}^{-2}$.

Impact of pulsed light on survival and growth of spoilage and pathogenic bacteria

Pulsed light process has been shown to be effective in inactivating a wide range of microorganisms (vegetative bacteria, moulds, bacterial, fungal spores...) involved in food products spoilage (Arrowood et al, 1996 ; Gómez-López et al, 2005 ; Lasagabaster and Martínez de Marañón, 2006 ; Martínez de Marañón and Gartzia, 2002 ; Roberts and Hope, 2003).

The specific mechanism by which pulsed light causes microbial inactivation still remains unclear. Different hypotheses have been proposed in the literature which could be due to the characteristics of the pulsed light devices like the peak power of each pulse, the kind of flashlamp and so on. The main inactivating effect of pulsed light could be attributed to UV inducing DNA-damages, such as formation of single strand breaks and pyrimidine and thymine dimers (Wang et al, 2005). Furthermore, Takeshita et al (2003) showed DNA damages and structural changes, such as cell membrane damage, when Saccharomyces cerevisiae was treated by pulsed light technology. These authors hypothesized that the high content in UV wavelengths of pulsed light could play an important role not only in DNA damages but also in cell structure modifications. Otherwise, Wekhof (2000) reported that pulsed light induced microbial inactivation could be attributed to cell disintegration after an instantaneous overheating of cellular constituents due to very high pulsed light doses. However, Rowan et al (1999) and Krishnamurthy et al (2004) found only minimal heating after pulsed light treatments inducing high levels of microbial inactivation, concluding that this high efficacy would be due to the effect of UV and not to a rise in temperature.

The impact of pulsed light to inactivate microorganisms isolated from fish products was studied (Lasagabaster and Martínez de Marañón, 2006) within the HURDLETECH project of SEAFOODplus IP. Results showed that a short treatment time $(325 \mu \mathrm{s})$ at relatively low dose induced high inactivation $\left(>7 \log _{10} \mathrm{CFU} \mathrm{ml^{-1 }}\right.$ or $\mathrm{cm}^{-2}$ ) of $L i$. innocua inoculated in liquids and on the surface of agar petri dishes, with no significant increase in samples temperature confirming previous results (see above). Pulsed light efficacy depended on the light dose received by microorganisms, which was modified by some process factors such as pulse energy, number of pulses... Li. innocua and Li. monocytogenes were the most pulsed light resistant bacteria among the different seafood spoiling and pathogenic strains studied. Therefore Li. innocua could be considered as a surrogate for Li. monocytogenes and as a reference microorganism for pulsed light treatment optimization in seafood products.

The impact of some physico-chemical factors on the effectiveness of pulsed light treatment was also determined for model media. Results showed that Li. innocua inactivation did not depend either on process temperature or $\mathrm{NaCl}$ concentration (up to $5 \%$ ). Moreover, cell concentration inoculated on solid models did not affect the pulsed light efficacy to inactivate $\mathrm{Li}$. innocua. However, this effectiveness would slightly depend on the physiological state of cells. 
Pulsed light technology has also been shown to be effective in inactivating $L i$. innocua from the surface of fish products such as CSS (Lasagabaster and Martínez de Marañón, 2006). Although microbial inactivation was less pronounced in inoculated seafood products (e.g. CSS, desalted cod) than in food models, the work performed within the HURDLETECH project pointed out that pulsed light processing could improve the safety (Listeria hazard) of seafood products. Moreover, pulsed light processing would increase the shelf life of CSS (by, at this stage of the project, taking into account only microbiological criteria).

Although more studies are needed, pulsed light technology appears as an efficient non-thermal decontamination process that could be applied to improve the safety and increase the shelf life of food products, in particular seafood products. Since the time required to inactivate microorganisms is very short, this technology could be successfully implemented in high-speed processing lines for the food industry.

\section{Future trends}

The convenience food trend is strong and is expected to continue through the coming years. The term convenient includes both the easy-to-use aspect, which is assumed to be most important for the consumers, and long shelf-life, which is important for the producers, distributors and shops to avoid loss.

Results presented in this chapter show that traditional preservation processes and more recently developed preservation methods may contribute to increase safety and quality of convenient seafood products. In some case, they may also introduce new food safety risks or unusual behaviour of the product that must be carefully taken into consideration (production of toxic metabolite, favourable conditions for unexpected pathogens, products that become unsafe before they are spoiled...). For that reason, results obtained in model media or with artificially inoculated seafood matrix (challenge tests) must be validated in real products, and all safety and quality aspects must be checked carefully.

Combination of different hurdles seems to be a very promising way to increase the antimicrobial effect. However, attention must be paid to the fact that bacteria submitted to a high stress (salt, acid, temperature, starvation etc...) may synthesise stress shock proteins that make them more tolerant to other stresses. This appears mainly when the preservative level is quite elevated. On the other hand, bacteria that are simultaneously submitted to various stresses require more energy to synthesise several shock proteins and become metabolically exhausted (Leistner et al, 2000). Therefore, lowering the level of each hurdle, which is also very interesting to maintain acceptable sensory characteristics, and applying them all together may be more efficient than using a single preservative at high concentration.

In some cases, not only a cumulative effect between hurdles but also a synergistic one has been observed. This is achieved if the hurdles at the same time hit different targets such as cell membrane, DNA, ribosome, proteins, enzyme system, intracellular pH etc... (Leistner, 1995 ; Maňas and Pagán, 2005). For that reason, elucidating the inhibitory mechanism of hurdles is of great importance to anticipate their adequate combination to get the most efficient effect.

In the future, it will be interesting to test different combinations of the preservative factors described in this chapter. Some of the studied hurdles are more efficient on 
spoiling microflora and other on pathogenic bacteria, therefore combining them could simultaneously enhance quality and safety of food.

Potential synergistic effects may be anticipated as the inhibiting mechanism varies within the tested hurdles. Enhancement of bioprotective bacteria growth has already been observed in presence of chitosan constituting a promising indicator of synergetic antimicrobial effect.

All the results presented in this chapter if completed by the suggested work could lead to a very efficient system for ensuring both quality and safety of seafood convenient products.

Source of further information and advice

Some sources on further information concerning :

- hurdle technology

Leistner L and Gould G W (2005), 'Update on hurdle technology approaches to food preservation', Antimicrobiol Food Third Ed, 143, 621-631.

- biopreservation

Rodgers S (2001), 'Preserving non-fermented refrigerated foods with microbial cultures-a review', Trends Food Science Technol, 12, 276-284.

Richard C, Leroi F, Brillet A, Rachman C, Connil N, Drider D, Pilet M F, Onno B, Dousset $X$ and Prevost $\mathrm{H}$ (2004), 'Control development of Listeria monocytogenes in smoked salmon: interest of the biopreservation by lactic bacteria', Lait, 84, 1-2, 135144.

Drosinos E H, Mataragas M and Metaxopoulos J (2005), 'Biopreservation: a new direction towards food safety', New Dev Food Policy Control Res, 31-64.

\section{- Chitosan}

Coma V, Martial-Gros A, Garreau S, Copinet A, Salin F (2002), 'Edible Antimicrobial Films Based on Chitosan Matrix', J. Food Sci., 67, 1162-1168.

\section{- Pulsed light}

Rowan N J, MacGregor S J, Anderson J G, Fouracre R A, Mcllvaney L, Farish O. (1999), 'Pulsed-light inactivation of food-related microorganisms', Appl Environ Microbiol, 65(3), 1312-1315.

\section{Results from the HURDLETECH project}

Cruz Z, Lauzon H L, Arboleya J C, Nuin M, Martínez de Marañón I and Amarita F (2006), 'Antmicrobial effect of chitosan on micro-organisms isolated from fishery product', in Luten J B, Jacobsen C, Bekaert K, Sæbø A and Oehlenschlager J, Seafood research from fish to dish: Quality, safety and processing of wild and farmed fish. Wageningen, Wageningen Academic Publishers, 387-393.

Lasagabaster A and Martínez de Marañón I.(2006),'Inactivation of microorganisms isolated from fishery products by pulsed light', in Luten J B, Jacobsen C, Bekaert K, Sæbø A and Oehlenschlager J, Seafood research from fish to dish: Quality, safety and processing of wild and farmed fish. Wageningen, Wageningen Academic Publishers, 381-386.

Matamoros S, Pilet M F, Prevost H and Leroi F (2006), 'Selection of psychotrophic bacteria active against spoilage and pathogenic micro-organisms relevant for seafood products', in Luten J B, Jacobsen C, Bekaert K, Sæbø A and 
Oehlenschlager J, Seafood research from fish to dish: Quality, safety and processing of wild and farmed fish. Wageningen, Wageningen Academic Publishers, 395-402.

Pilet, M F, Brillet A, . Matamoros S, Blanchet-Chevrollier C, Leroi F and Prévost $\mathrm{H}$ (2006), 'Selection of non-tyramine producing Carnobacterium strains for the biopreservation of cold smoked salmon', in Luten J B, Jacobsen C, Bekaert K, Sæbø A and Oehlenschlager J, Seafood research from fish to dish: Quality, safety and processing of wild and farmed fish. Wageningen, Academic Publishers, 403-410.

\section{References}

Ahn C B, Lee E H (1992),'Utilization of chitin prepared from the shellfish crust. 2. Effect of chitosan film packing on quality of lightly-salted and dried horse mackerel', Bull Korean Fish Soc, 25 (1), 51-57.

Altieri C, Speranza B, Del Nobile M A. and Sinigaglia M (2005), 'Suitability of bifidobacteria and thymol as biopreservatives in extending the shelf life of fresh packed plaice fillets', J Appl Microbiol, 99, 1294-1302.

Arrowood MJ, Xie LT, Rieger K and Dunn J (1996), 'Disinfection of Cryptosporidium parvum oocysts by pulsed light treatment evaluated in an in vitro cultivation model', $J$ Eukaryotic Microbiol, 43 (5), 88S.

Barat J M, Gallart-Jornet L, Andrés A, Akse L, Carlehög M, Skjerdal O T (2006), 'Influence of cod freshess on the salting, drying and desalting stages', J Food Eng, 73, 6-19

Bhugaloo-Vial P, Dousset X, Metivier A, Sorokine O, Anglade P, Boyaval P and Marion D (1996), 'Purification and amino acid sequences of piscicocins V1a and V1b, two class Ila bacteriocins secreted by Carnobacterium piscicola V1 that display significantly different levels of specific inhibitory activity', Appl Env Microbiol, 62, 4410-6.

Bjørkevoll I, Olsen R L, Skjerdal O T (2003), 'Origin and spoilage potential of the microbiota dominating genus Psychrobacter in sterile rehydrated salt-cured and dried salt-cured cod (Gadus morhua)', Int J Food Microbiol, 84, 175-187.

Brillet A, Pilet M F, Prevost H, Cardinal M and Leroi F (2005), 'Effect of inoculation of Carnobacterium divergens V41, a biopreservative strain against Listeria monocytogenes risk, on the microbial, chemical and sensory quality of cold-smoked salmon', Int J Food Microbiol, 104, 309-324.

Brillet A, Pilet M. F, Prevost H, Bouttefroy A and Leroi F (2004), 'Biodiversity of Listeria monocytogenes sensitivity to bacteriocin-producing Carnobacterium strains and application in sterile cold-smoked salmon', J Appl Microbiol, 97, 1029-1037.

Butler BL, Vergano PJ, Testin RF, Bunn JM and Wiles JL (1996), 'Mechanical and barrier properties of edible chitosan films as affected by composition and storage', $J$ Food Sci, 61 (5), 953-956.

Caner C, Vergano PJ, and Wiles JL (1998), 'Chitosan film mechanical and permeation properties as affected by acid, plasticizer, and storage', J Food Sci, 63 (6), 1049-1053.

Chen CS, Liau WY and Tsai GJ (1998), 'Antibacterial Effects of N-Sulfonated and Nsulfobenzoyl Chitosan and Application to Oyster Preservation', J Food Prot, 61, 1124-1128.

Coma V, Martial-Gros A, Garreau S, Copinet A, and Salin F (2002), 'Edible Antimicrobial Films Based on Chitosan Matrix', J Food Sci, 67, 1162-1168.

Cornu M, Beaufort A, Rudelle S, Laloux L, Bergis $H$, Miconnet $N$, Serot $T$ and Delignette-Muller M L (2006), 'Effect of temperature, water-phase salt and phenolic contents on Listeria monocytogenes growth rates on cold-smoked salmon and evaluation of secondary models', Int J Food Microbiol, 106, 159-68. 
Cruz Z, Lauzon HL, Arboleya JC, Nuin M, Martínez de Marañón I and Amarita F (2006), 'Antmicrobial effect of chitosan on micro-organisms isolated from fishery product', in Luten J B, Jacobsen C, Bekaert K, Sæbø A and Oehlenschlager J, Seafood research from fish to dish: Quality, safety and processing of wild and farmed fish, Wageningen, Wageningen Academic Publishers, 387-393.

Cuero RG and Osuji G, Washington A (1991), 'N-carboxymethyl chitosan inhibition of aflatoxin production: role of zinc', Biotechnol Lett, 13, 441-444.

Dalgaard P (1995), 'Qualitative and Quantitative Characterization of Spoilage Bacteria from Packed Fish', Int J Food Microbiol, 26, 319-333.

Daniel Pand Lorre S (2003), 'Novel lactic acid bacteria of the genus Lactococcus lactis and use thereof for preserving food products', Patent $N^{\circ}$ W003027268.

Drider D, Fimland G, Hechard Y, McMullen L M and Prevost H (2006), 'The continuing story of class Ila bacteriocins', Microbiol Mol Biol Rev, 70, 564-82.

Duffes F, Corre C, Leroi F, Dousset X and Boyaval P (1999), 'Inhibition of Listeria monocytogenes by in situ produced and semipurified bacteriocins of Carnobacterium spp. on vacuum-packed, refrigerated cold-smoked salmon', J Food Prot, 62, 1394403.

Dunn J, Ott T and Clark W (1995), 'Pulsed-light treatment of food and packaging', Food Technol, 49, 95-98.

Dunn J, Salisbury K, Bushnell A and Clarke W (1997), 'Sterilization using pulsed white light', Med Device Technol, 8 (6), 24-26.

European-Comission (1994), 'Directive 94/40/EC of 22 july 1994 amending Council Directive 87/153/EEC fixing guidelines for the assessment of additives in animal nutrition'.

European-Comission (2003), 'On a generic approach to the safety assessment of micro-organisms used in feed/food and feed/food production'.

European-Parliament-and-Council (1997), 'Regulation (EC) $\mathrm{N}^{\circ} 258 / 97$ of the European Parliament and of the Council of 27 january 1997 concerning novel foods and novel food ingredients'.

FDA (2003), 'Pulsed light for the treatment of food', Code of Federal Regulations 21CFR179.41, 443.

Fernández-Segovia I, Escriche I, Gomez-Sintes M, Fuentes A, Serra J A (2006), 'Influence of different preservation treatments on the volatile fraction of desalted cod', Food Chem, 98, 473-482.

Fernández-Segovia I, Garrigues R, Carot J M, Escriche I (2003), 'Improvement in the microbiological quality of ready-to-use desalted cod', J Food Sci, 68, 2553-2557.

Gemma H and Du J (1996), 'Effect of Application of Various Chitosans with different Molecular Weights on the Storability of Jonagold Apple', ISHS Acta Horticulturae 464: International Postharvest Science Conference.

Genta I, Giunchedi P, Pavanetto F, Conti B, Perugini P and Conte U (1997), 'Preparation of Chitosan microparticulate drug delivery systems', in Muzzarelli RAA and Muzzarelli C, Chitin Handbook; European Chitin Society, Grottammare, Atec Publisher, 391-404

Gómez-López VM, Devlieghere F, Bonduelle V and Debevere J (2005), 'Factors affecting the inactivation of microorganisms by intense light pulses', J Appl Microbiol, 99 (3), 460-470.

Helander IM, Nurmiaho-Lassila EL, Ahvenainen R, Rhoades J and Roller S (2001), 'Chitosan disrupts the barrier properties of the outer membrane of gram-negative bacteria', Int J Food Microbiol, 71(2-3), 235-44.

Hoffman A D, Gall K L, Norton D M and Wiedmann M (2003), 'Listeria monocytogenes contamination patterns for the smoked fish processing environment and for raw fish', J Food Prot, 66, 52-60.

Huss H H, Jorgensen L V and Vogel B F (2000), 'Control options for Listeria monocytogenes in seafood', Int J Food Microbiol, 62, 267-74. 
Hwang KT, Kim JT, Jung ST, Cho GS and Park HJ (2003), 'Properties of chitosanbased biopolymer films with various degrees of deacetylation and molecular weights', J Appl Polym Sci, 89 (13), 3476-3484.

Jeon YJ, J Kamil and Shahidi F (2002), 'Chitosan as an edible invisible film for quality preservation of herring and Atlantic cod', J Agric Food Chem, 50(18), 5167-5178.

Jorgensen LV and Huss $\mathrm{H} \mathrm{H}$ (1998), 'Prevalence and growth of Listeria monocytogenes in naturally contaminated seafood', Int J Food Microbiol, 42, 127131.

Katla T, Moretro T, Aasen I M, Holck A, Axelsson L and Naterstad K (2001), 'Inhibition of Listeria monocytogenes in cold smoked salmon by addition of sakacin P and/or live Lactobacillus sakei cultures', Food Microbiol, 18, 431-439.

Kim JG Yousef AE and Dave S (1999), 'Application of ozone for enhancing the microbiological safety and quality of foods: a review', J Food Prot, 62, 1071-1087.

Krishnamurthy K, Demirci A and Irudayaraj J (2004), 'Inactivation of Staphylococcus aureus by pulsed UV-light sterilization', J Food Prot, 67 (5), 1027-1030.

Lasagabaster A and Martínez de Marañón I (2006), 'Inactivation of microorganisms isolated from fishery products by pulsed light', in Luten JB, Jacobsen C, Bekaert K, Sæbø A and Oehlenschlager J, Seafood research from fish to dish; quality, safety and processing of wild and farmed fish, Wageningen, Wageningen Academic Publishers, 381-386.

Laursen B G, Bay L, Cleenwerck I, Vancanneyt M, Swings J, Dalgaard P and Leisner J J (2005), 'Carnobacterium divergens and Carnobacterium maltaromaticum as spoilers or protective cultures in meat and seafood: phenotypic and genotypic characterization', Syst Appl Microbiol, 28, 151-164.

Leistner L (1985), 'Hurdle technology applied to meat products of the shelf stable product and intermediate moisture food types', in Simatos D and Multon J L, Properties of Water in Foods in Relation to Quality and Stability, Dordrecht, Martinus Nijhoff, 309-329.

Leistner L (1995), 'Principle and application of hurdle technology' in Gould G W, New Methods for Food Preservation, London, Blakie Academic and professional, 1-21.

Leistner L (2000), 'Basic aspect of food preservation by hurdle technology', Int J Food Microbiol, 55, 181-186.

Leroi F, Arbey N, Joffraud JJ and Chevalier F (1996), 'Effect of inoculation with lactic acid bacteria on extending the shelf life of vacuum-packed cold smoked salmon', Int J Food Sci Technol, 31, 497-504.

Leroi F, Joffraud J J, Chevalier F and Cardinal M (1998), 'Study of the microbial ecology of cold-smoked salmon during storage at 8 degrees C', Int J Food Microbiol, $39,111-21$.

Leroy $F$ and De Vuyst $L$ (1999), 'The presence of salt and a curing agent reduces bacteriocin production by Lactobacillus sakei CTC 494, a potential starter culture for sausage fermentation', Appl Environ Microbiol, 65 (12), 5350-5356.

Magnússon H, Sveinsdóttir K, Lauzon H L, Thorkelsdóttir A, Martinsdóttir E (2006), 'Keeping quality of desalted cod fillets in consumer packs', J Food Sci, 71, M69-M76. Mahmoud BSM, Yamasaki K, Miyashita K, Kawai Y, Shin IS. and Suzuki T (2006), 'Preservative effect of combined treatment with electrolysed $\mathrm{NaCl}$ solutions and essential oil compounds on carp fillets during convectional air-drying', Int J Food Microbiol, 106, 331-337.

Maňas P and Pagán R (2005), 'Microbial inactivation by new technologies of food preservation', J Appl Microbiol, 98, 1387-1399.

Martínez de Marañón I, Gartzia I (2002), 'Non-thermal treatments to food preservation: Pulsed Light', Symposium on Emerging Technologies for the Food Industry, Madrid (Spain), 199.

Métivier A, Pilet M F, Dousset X, Sorokine O, Anglade P, Zagorec M., Piard J. C, Marion D, Cenatiempo $Y$ and Fremaux C (1998), 'Divercin V41, a new bacteriocin 
with two disulphide bonds produced by Carnobacterium divergens V41: primary structure and genomic organization', Microbiology, 144, 2837-2844.

Meyer H L (2005), 'La bioprotection élargit son périmètre', RIA, 659, 57-58.

Miettinen H and Wirtanen G (2005), 'Prevalence and location of Listeria monocytogenes in farmed rainbow trout', Int J Food Microbiol, 104, 135-43.

Montville TJ and Winkowski K (1997), 'Biologically-based preservation systems and probiotic bacteria', in Doyle MP, Beuchat LR, Montville TJ, Food microbiology: fundamentals and frontiers, Washington DC, American Society for Microbiology Press, 557-577.

Nadarajah K, Prinyawiwatkul W, No HK, Sathivel S, and Xu Z (2006), 'Sorption behavior of crawfish chitosan films as affected by chitosan extraction processes and solvent types', J Food Sci, 71 (2), 33-39.

Nakamura H, Hatanaka M, Ochi K, Nagao M, Ogasawara J, Hase A, Kitase T, Haruki $\mathrm{K}$ and Nishikawa $\mathrm{Y}$ (2004), 'Listeria monocytogenes isolated from cold-smoked fish products in Osaka City, Japan', Int J Food Microbiol, 94, 323-8.

Nilsson L, Gram L and Huss H H (1999), 'Growth control of Listeria monocytogenes on cold-smoked salmon using a competitive lactic acid bacteria flora', J Food Prot, 62, 336-42.

Nilsson L, Hansen T B, Garrido P, Buchrieser C, Glaser P, Knochel S, Gram L and Gravesen A (2005), 'Growth inhibition of Listeria monocytogenes by a nonbacteriocinogenic Carnobacterium piscicola', J Appl Microbiol, 98, 172-83.

Olabarrieta I (2005), 'Strategies to improve the aging, barrier and mechancial properties of chitosan, whey and wheat gluten protein films', Ph.D. thesis, Chemical Science and Engineering-KTH, Stockholm, KTH.

Paludan-Muller C, Dalgaard P, Huss H H and Gram L (1998), 'Evaluation of the role of Carnobacterium piscicola in spoilage of vacuum- and modified-atmospherepacked cold-smoked salmon stored at 5 degrees C', Int J Food Microbiol, 39, 155-66. Park SY, Marsh KS and Rhim JW (2002), 'Characteristics of different molecular weight chitosan films affected by the type of organic solvents', J Food Sci, 67 (1), 194-197.

Pedro S, Albuquercque M, Nunes L, Bernardo F (2004), 'Pathogenic bacteria and indicators and salted cod (gadus morhua) and desalted products at low and high temperatures', J Aqua Food Prod Technol, 13, 39-49.

Ray B (1992), 'The need for biopreservatives', in Ray B and Daeschel MA, Food biopreservatives of microbial origin, Boca Raton, CRC Press, 1-23.

Rhoades J and Roller S (2000), 'Antimicrobial actions of degraded and native chitosan against spoilage organisms in laboratory media and foods', Appl Environ Microbiol, 66 (1), 80-6.

Ribeiro Neunlist M, Ralazamahaleo M, Cappelier J M, Besnard V, Federighi M and Leroi $F$ (2005), 'Effect of salting and cold-smoking process on the culturability, viability, and virulence of Listeria monocytogenes strain Scott A', J Food Prot, 68, 8591.

Richard C, Brillet A, Pilet M F, Prevost H and Drider D (2003), 'Evidence on inhibition of Listeria monocytogenes by divercin V41 action', Lett Appl Microbiol, 36, 288-92.

Roberts P and Hope A (2003), 'Virus inactivation by high intensity broad spectrum pulsed light', J Virol Methods, 110, 61-65.

Rodgers S (2001), 'Preserving non-fermented refrigerated foods with microbial cultures-a review', Trends Food Sci Technol, 12, 276-284.

Roller S (2002), 'Chitosan, a novel food preservative?' in Muzzarelli R A A and Muzzarelli C, Chitosan in Pharmacy and Chemistry, Atec, Italy, 177-193

Roller S (2003), 'Chitosan: a new food preservative or laboratory curiosity?', in Roller S, Natural antimicrobials for the minimal processing of foods, Cambridge, CRC Press, 159-175.

Roller S and Covill N (1999), 'The antifungal properties of chitosan in laboratory media and apple juice', Int J Food Microbiol, 47 (1-2), 67-77. 
Rowan NJ, MacGregor SJ, Anderson JG, Fouracre RA, Mcllvaney L and Farish O (1999), 'Pulsed-Light inactivation of food-related microorganisms', Appl Environ Microbiol, 65 (3), 1312-1315.

Sathivel S (2005), 'Chitosan and protein coatings affect yield, moisture loss, and lipid oxidation of pink salmon (Oncorhynchus gorbuscha) fillets during frozen storage', $\mathrm{J}$ Food Sci, 70(8), E455-E459.

Shahidi F, Kamil J, Arachchi V and Jeon YJ (1999), 'Food aplications of chitin and chitosans', Trends Food Sci Tec, 10, 37-51

Simpson BK, Gagne N, Ashie IN A and Noorozi E (1997), 'Utilization of Chitosan for Preservation of Raw Shrimp Pandalus Borealis', Food Biotech, 11, 25-44.

Skjerdal O T, Pedro S, Serra J A (2002), 'Improved quality and shelf life of desalted cod, an easy- to-use product of salted cod', Final Report to the European Commision. FAIR Project CT98-4179, pp. 89.

Skonberg DI (2000), 'Extending shelf life of fresh fish fillets with chitosan coating', IFT 2000 Annual Meeting (abstract).

Srinivasa PC, Ramesh MN, Kumar KR and Tharanathan RN (2004), 'Properties of chitosan films prepared under different drying conditions', J Food Eng, 63 (1), 79-85.

Stohr V, Joffraud J J, Cardinal M and Leroi F (2001), 'Spoilage potential and sensory profile associated with bacteria isolated from cold-smoked salmon', Food Res Int, 34, 797-806.

Suyatma NE, Tighzert L and Copinet A (2005), 'Effects of hydrophilic plasticizers on mechanical, thermal, and surface properties of chitosan films', J Agric Food Chem, 53 (10), 3950-3957.

Takeshita K, Shibato J, Sameshima T, Fukunaga S, Isobe S, Arihara K and Itoh M (2003), 'Damage of yeast cells induced by pulsed light irradiation', Int J Food Microbiol, 85, 151-158.

Tsai GJ, Wen-huey S, Hsing-Chen C and Chorng-laing P (2002), 'Antimicrobial activity of shrimp chitin and chitosan from different treatments and applications of fish preservation', Fish Sci, 68,170

Tsai GJ, Wu ZY and Su WH (2000), 'Antibacterial activity of a chitooligosacharide mixture prepared by cellulase digestion of shrimp chitosan and its application to milk preservation', J Food Prot, 63 (6),747-52.

Verluyten J, Schrijvers V, Leroy F and De Vuyst L (2002), 'Modelling the behaviour of the potential meat starter culture Lactobacillus curvatus LTH 1174 as influenced by different environmental factors important for European sausage fermentations', Proceedings of the 18th International ICFMH Symposium FOOD MICRO 2002, 167172, Lillehammer, Norway, August 18-23.

Vescovo M, Scolari G and Zacconi C (2006), 'Inhibition of Listeria innocua growth by antimicrobial-producing lactic acid cultures in vacuum-packed cold smoked salmon', Food Microbiol, 23, 689-693.

Vilhelmsson O, Hafsteinsson $\mathrm{H}$, Kristjánsson J K (1997), 'Extremely halotolerant bacteria characteristic of fully cured and dried cod', Int J Food Microbiol, 36, 163-170.

Wang T, MacGregor SJ, Anderson JG and Woolsey GA (2005), 'Pulsed ultra-violet inactivation spectrum of Escherichia coli', Water Res, 39, 2921-2925.

Weber D E (2000), 'Kinetics of microbial inactivation for alternative food processing technologies', J Food Sci Special supplement, 65, 1-107.

Wekhof A (2000), 'Disinfection with flash lamps', J Pharm Sci and Technol, 54, 264276.

Wessels S, Axelsson L, Hansen E B, De Vuyst L, Laulund S, Lahteenmaki L, Lindgren S, Mollet B, Salminen S and von Wright A (2004), 'The lactic acid bacteria, the food chain, and their regulation', Trends Food Sci Technol, 15, 498-505.

Yamazaki K, Suzuki M. Kawai Y, Inoue N and Montville T J (2003), 'Inhibition of Listeria monocytogenes in cold-smoked salmon by Carnobacterium piscicola CS526 isolated from frozen surimi', J Food Prot, 66, 1420-5. 
Tables

\begin{tabular}{lcccccc}
\hline Days & \multicolumn{5}{c}{$\mathrm{NaCl}(\%)$} \\
\cline { 2 - 6 } & 5 & 9 & 12 & 15 & 18 & 21 \\
\cline { 2 - 6 } Li. innocua & & & & & \\
3 & $+/+/+$ & $+/+/+$ & $+/+/+$ & $+/+/+$ & $+/+/+$ & $+/+/+$ \\
21 & $+/+/+$ & $+/+/+$ & $+/+/+$ & $+/+/+$ & $+/+/+$ & $+/+/+$ \\
St. xylosus & & & & & & \\
3 & $+/+/+$ & $+/+/+$ & $+/+/+$ & $+/+/+$ & $+/+/+$ & $+/+/+$ \\
7 & $+/+/-$ & $+/+/-$ & $+/+/-$ & $+/+/-$ & $+/+/-$ & $+/-/+$ \\
10 & $+/+/-$ & $+/+/+$ & $+/+/+$ & $+/+/+$ & $+/+/+$ & $+/-/-$ \\
13 & $+/+/+$ & $+/+/-$ & $+/+/-$ & $+/+/-$ & $+/-/-$ & $+/-/-$ \\
17 & $+/+/-$ & $+/+/-$ & $+/+/-$ & $+/-/+$ & $+/-/-$ & $+/-/-$ \\
21 & $+/+/+$ & $+/+/-$ & $+/-/+$ & $+/-/-$ & $+/-/-$ & $+/-/-$ \\
\hline
\end{tabular}

Table 1 Survival of Listeria innocua and Staphylococcus xylosus during exposure to salted fish juice, incubated at $4{ }^{\circ} \mathrm{C}$ from 3 to 21 days. Detection of colony forming bacteria are presented as + present or - absent, for inoculation levels $10^{9} / 10^{7} / 10^{5}$ CFU mll ${ }^{-1}$, respectively.

\begin{tabular}{|c|c|c|c|c|c|}
\hline \multirow{2}{*}{$\begin{array}{l}\text { 18. Experi } \\
\text { ment }\end{array}$} & \multirow{2}{*}{$\begin{array}{l}\text { 19. Inoculated } \\
\text { bacteria }\end{array}$} & \multicolumn{4}{|c|}{ 20. Listeria level ( $\log _{10} \mathrm{CFU} \mathrm{g}^{-1}$ fish) } \\
\hline & & 21. Prior to & 22. After & 23. During & 24. During storage \\
\hline & & salt-curing & rehydration & storage at $4{ }^{\circ} \mathrm{C}$, & at $8^{\circ} \mathrm{C}$, after $5 / 10$ \\
\hline & & & & after $5 / 10$ days & days \\
\hline 25. 1 & 26. Li. innocua & 27. $1.0^{*}$ & 28. nd & 29. nd/nd & 30. $\mathrm{nd} / 5.0$ \\
\hline 2 & Li. innocua & 2.7 & 1.7 & $1.6 / 2.8$ & 3.0/6.7 \\
\hline 3 & Li. innocua & 4.5 & 4.0 & $3.7 / 4.5$ & $4.4 / 8.0$ \\
\hline 4 & Li. innocua & 6.3 & 5.6 & $5.3 / 7.2$ & $7.9 / 8.6$ \\
\hline 5 & none & nd & nd & $\mathrm{nd} / \mathrm{nd}$ & nd \\
\hline
\end{tabular}




\begin{tabular}{llllll}
\hline 6 & Li. monocytogenes & na & 4.3 & $4.6^{\star \star}$ & na \\
7 & Li. innocua & na & 5.4 & $5.6^{\star \star}$ & na \\
8 & none & nd & nd & nd $^{\star \star}$ & na
\end{tabular}

* estimated, below detection level

** after 8 days of storage

na: not analysed

nd: not detected, below $1.7 \log _{10}$ CFU g ${ }^{-1}$ fish

Table 2 Levels of Listeria innocua CCUG 15531 T (experiments 1-4, 7) and Listeria monocytogenes no 4006 (experiment 6) in cod prior to salt-curing, after rehydration and during storage at 4 and $8{ }^{\circ} \mathrm{C}$. Experiment 5 and 8 are uninoculated controls.

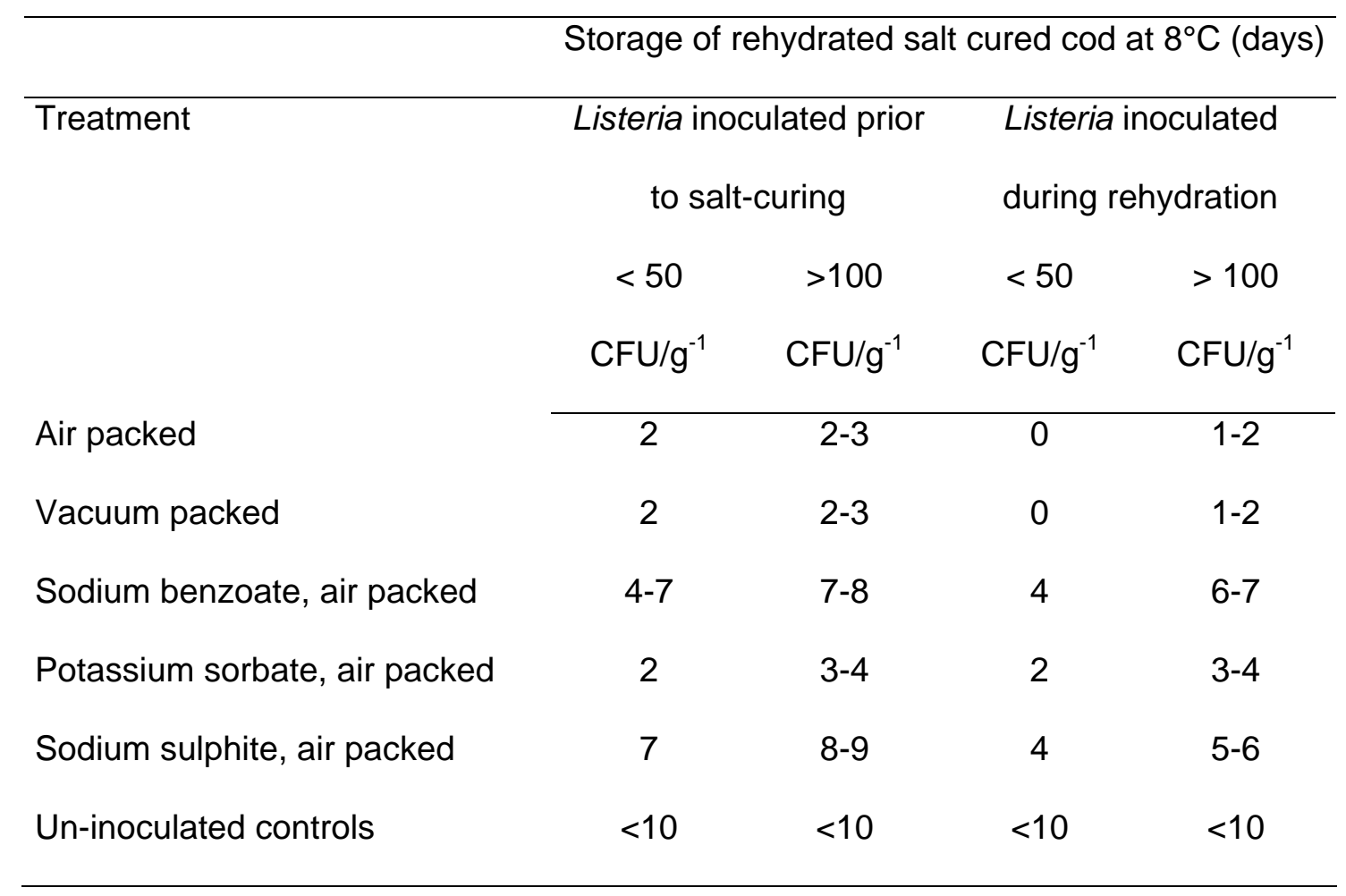

Table 3 Days until the Listeria innocua level in rehydrated salt-cured cod during storage reached 50 and $100 \mathrm{CFU} / \mathrm{g}^{-1}$, respectively, of rehydrated salt-cured cod. The fish was inoculated with app $10 \mathrm{CFU} / \mathrm{g}^{-1}$ fish either prior to salt-curing or during rehydration. 


\section{Figures}
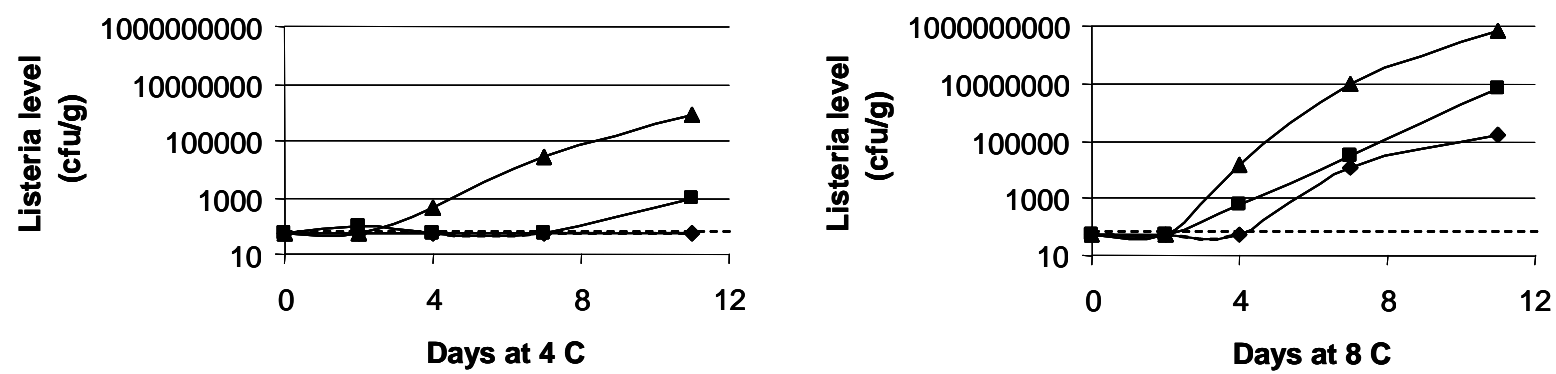

$\longrightarrow$ inoculated prior to salt-curing, $<20 \mathrm{cfu} / \mathrm{g}$
$\rightarrow-$ inoculated prior to salt-curing, $500 \mathrm{cfu} / \mathrm{g}$
$\longrightarrow \_$Inoculated during rehydration, $10 \mathrm{cfu} / \mathrm{g}$
--- detection level, $50 \mathrm{cfu} / \mathrm{g}$

Figure 1 Growth of Listeria innocua in rehydrated salt-cured cod. The fish was

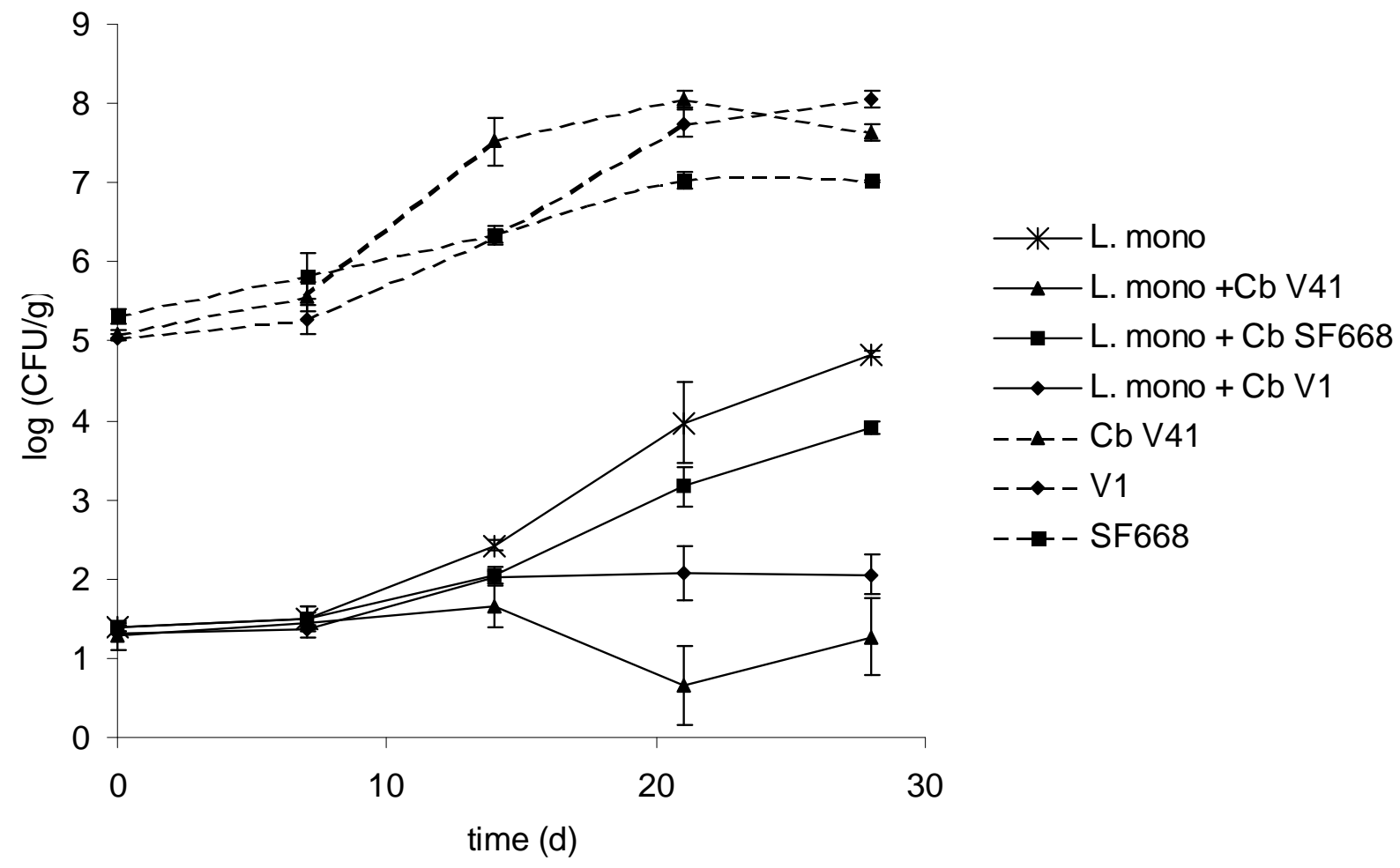

contaminated either prior to salt-curing or during rehydration.

Figure 2 Growth of Listeria monocytogenes (mix of 5 strains) and protective Carnobacterium strains co-inoculated in cold smoked salmon stored under vacuum 
for 9 days at $4^{\circ} \mathrm{C}$ and 19 days at $8^{\circ} \mathrm{C}$ (with a break of $2 \mathrm{~h}$ at $20^{\circ} \mathrm{C}$ after 19 days). Mean of three experiments.

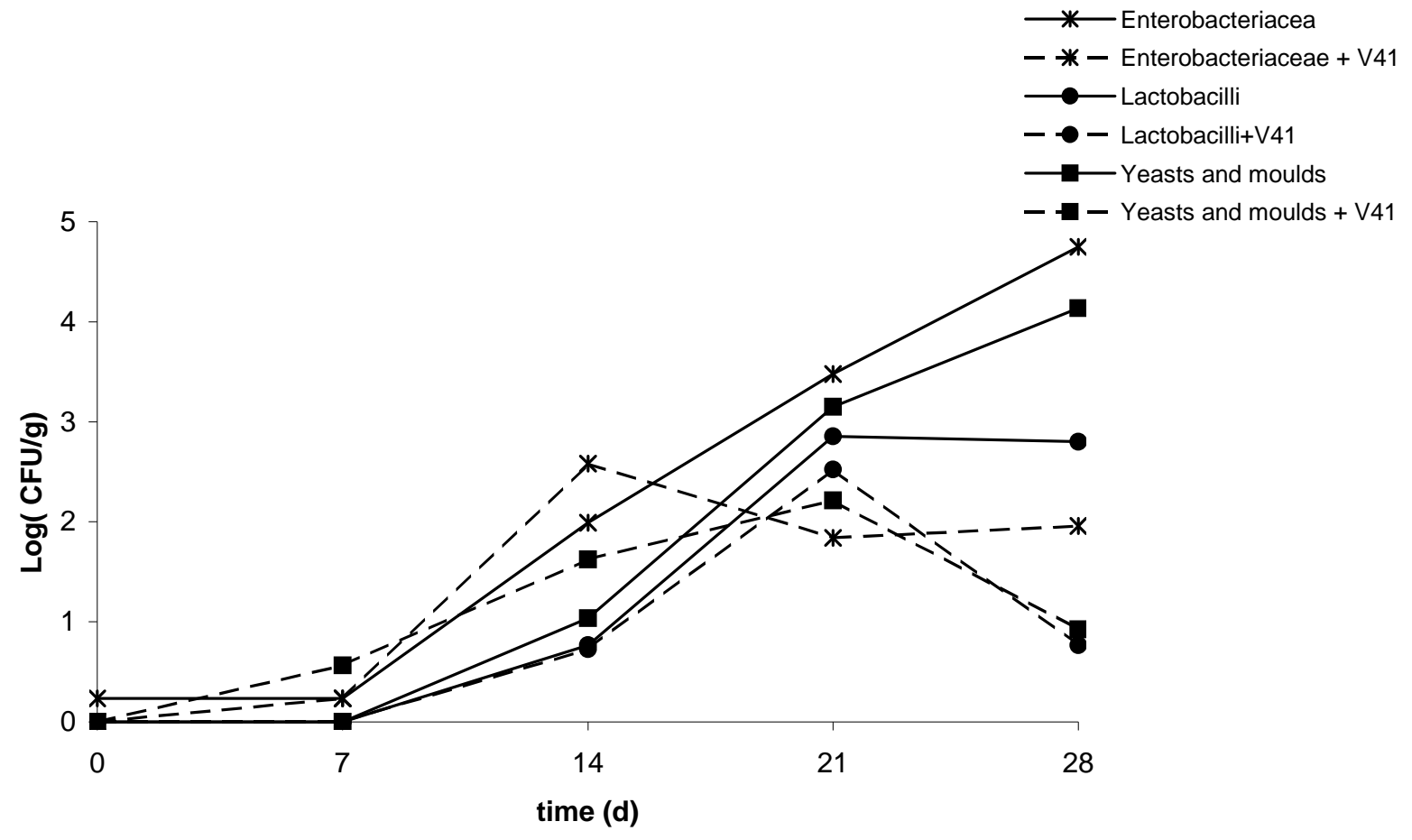

Figure 3 Growth of Enterobacteriaceae, lactobacilli and yeasts and moulds in presence or absence of Carnobacterium divergens V41 in commercial cold smoked salmon stored under vacuum for 9 days at $4^{\circ} \mathrm{C}$ and 19 days at $8^{\circ} \mathrm{C}$ (with a break of $2 \mathrm{~h}$ at $20^{\circ} \mathrm{C}$ after 19 days). Straight line : control ; dashed line : inoculated with $\mathrm{C}$ .divergens V41. Mean of three experiments. 


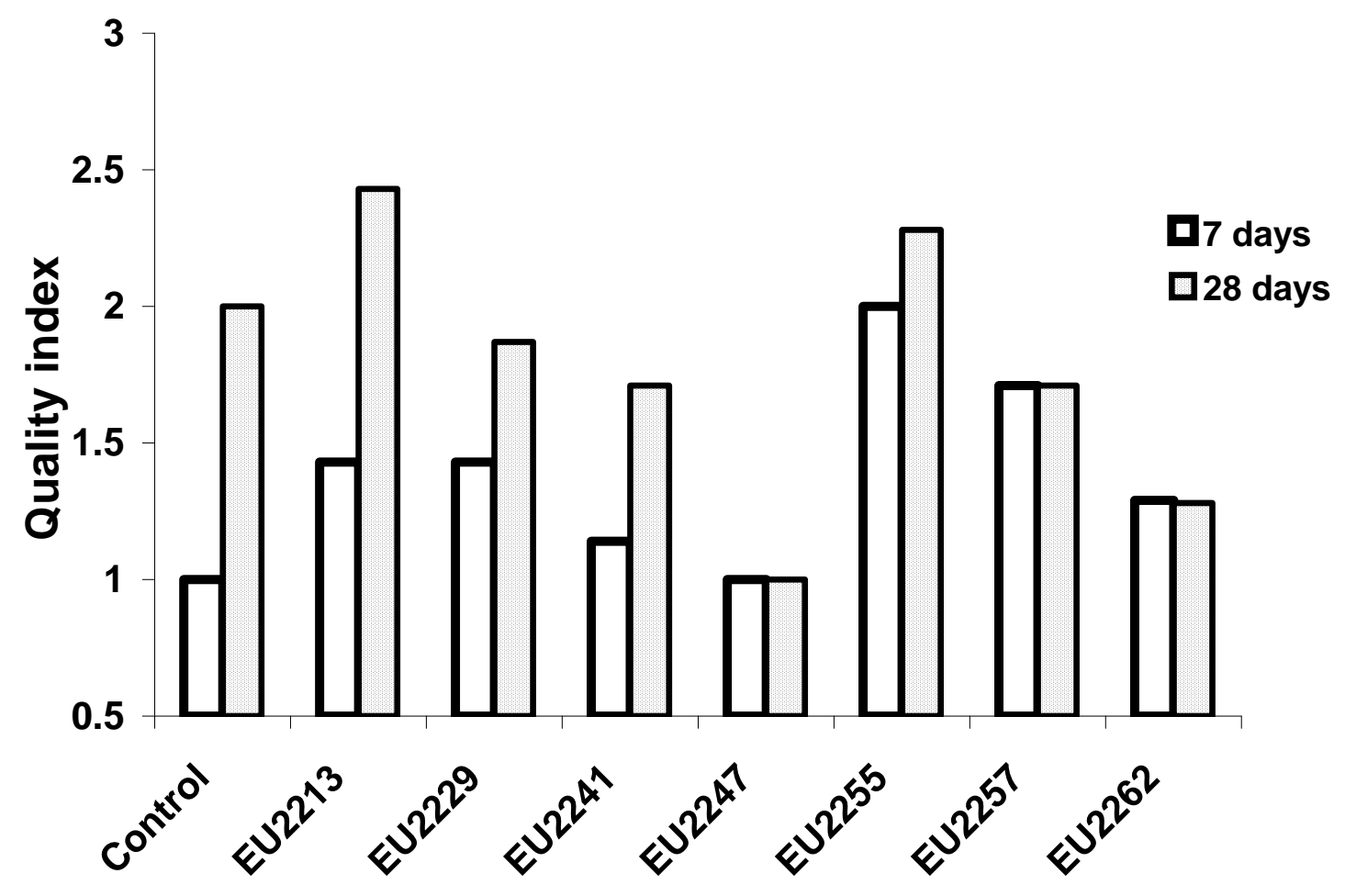

Figure 4 Evolution of the Quality Index of cooked peeled shrimps (batch 1) inoculated with seven different strains of bioprotective lactic acid bacteria $\left(10^{5} \mathrm{UFC} / \mathrm{g}\right)$, after 7 days and 28 days of storage under vacuum at $8^{\circ} \mathrm{C}$. Control : non inoculated sample. EU2213, 2247, 2262 : Leuconostoc gelidum ; EU 2229, 2241 : Lactococcus piscium ; EU2257 : Carnobacterium alterfunditum ; EU2255 : Lactobacillus fuchuensis 


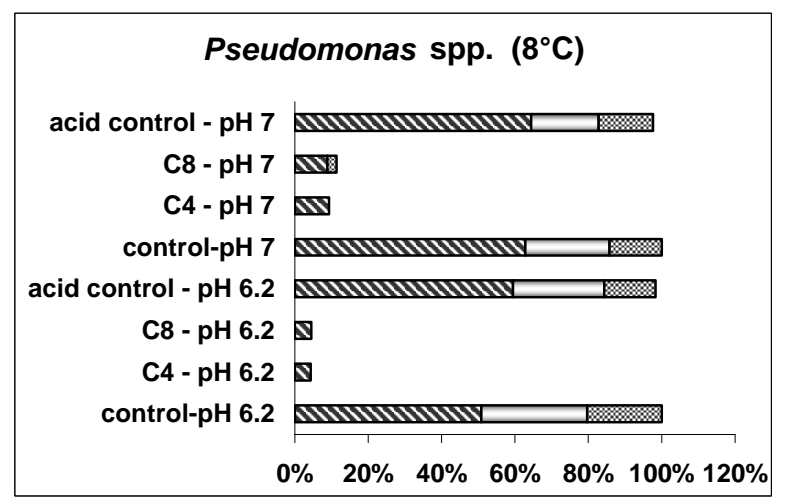

\section{L. monocytogenes $\left(8^{\circ} \mathrm{C}\right)$}

acid control - pH 7 WMU

C8 - $\mathrm{pH} 7 \mathrm{MIM}$

C4 - pH 7 आपाया

control-pH 7

acid control - pH 6.2 MIU!r

C8 - pH 6.2 anv

C4 - pH 6.2 WI

control-pH 6.2

$\begin{array}{lllllll}0 \% & 20 \% & 40 \% & 60 \% & 80 \% & 100 \% & 120 \%\end{array}$

\section{C. divergens $\mathrm{V} 41\left(8^{\circ} \mathrm{C}\right)$}

acid control - pH 7 19.

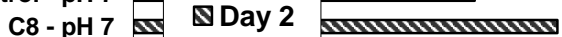

C4 - pH 7 aII

control-pH 7

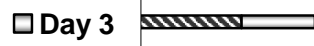

Day 6

acid control - pH 6.2 काष

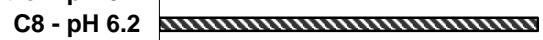

C4 - pH 6.2 \$11

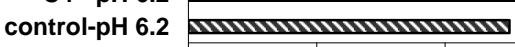

$0 \% \quad 40 \% \quad 80 \% \quad 120 \%$

Maximum growth \%

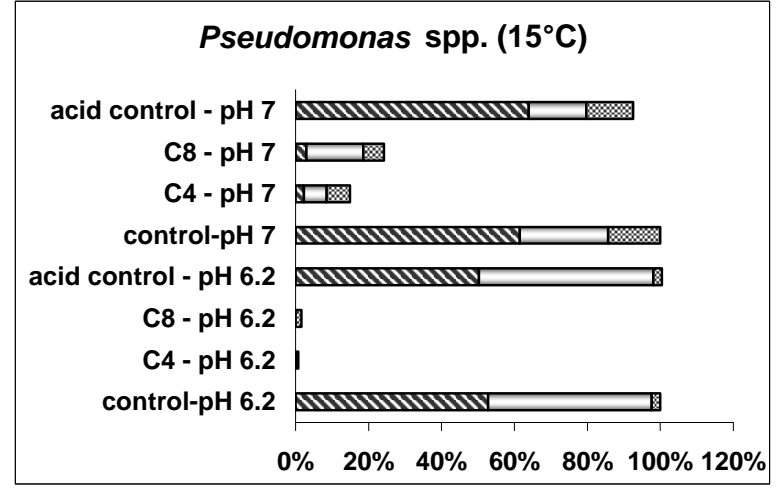

L. monocytogenes $\left(15^{\circ} \mathrm{C}\right)$

acid control - pH 7 Mपणपणपण

C8 - pH 7 \$

C4 - pH 7 М

control-pH 7 Мापापूपाप

acid control - pH 6.2 MIV

C8 - pH 6.2 जाप

C4 - pH 6.2 जाए

control-pH 6.2

$\begin{array}{lllllll}0 \% & 20 \% & 40 \% & 60 \% & 80 \% & 100 \% & 120 \%\end{array}$

\section{C. divergens $\mathrm{V} 41\left(15^{\circ} \mathrm{C}\right)$}

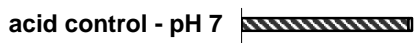

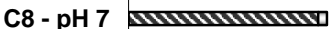

C4 - pH 7 आयापायापा

\$ Day 1

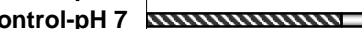

acid control - pH 6.2 आपापापयापा

图 Day 3

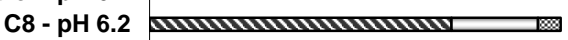

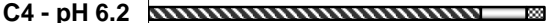

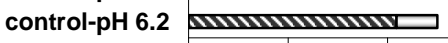

$$
0 \% \quad 40 \% \quad 80 \% \quad 120 \% \quad 160 \%
$$

Maximum growth \%

Figure 5 Bacterial development (\% maximum growth) in cold-smoked salmon juice (control) at pH 6.2 and 7 over a time period at $8^{\circ}$ and $15^{\circ} \mathrm{C}$, in presence of acidified chitosan preparations (C4 or $\mathrm{C} 8$ ) or acid control (acidified solvent with no added chitosan). Results shown are an average of 2 measurements. 


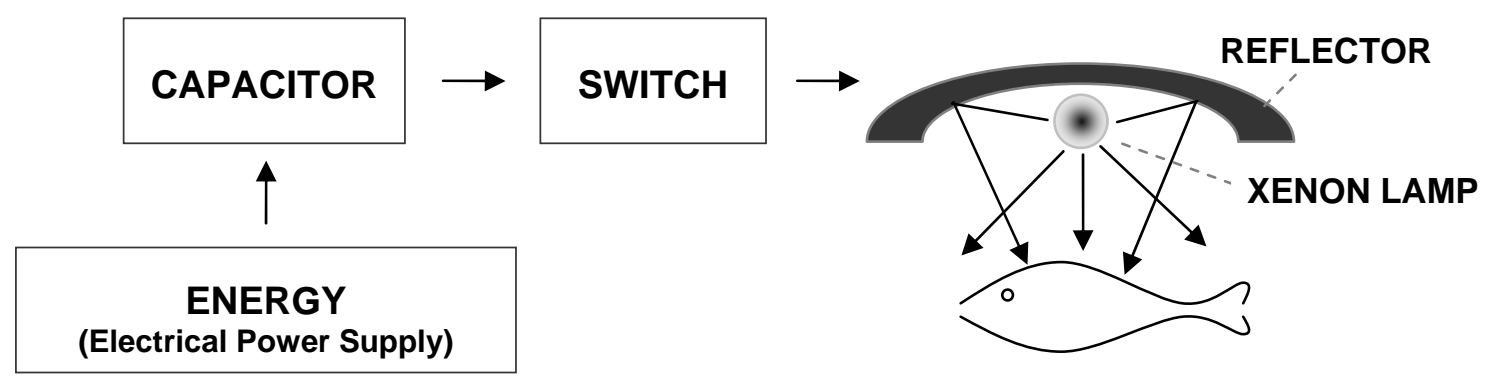

Figure 6 Pulsed light process 